\title{
Free sialic acid levels in the cerebrospinal fluid of patients with meningitis
}

\author{
TAUSIF ALAM, REBECCA CHERIAN, P. T. RAMAN, AND \\ A. S. BALASUBRAMANIAN \\ From the Neurochemistry Laboratory, Department of Neurological Sciences, Christian Medical College \\ Hospital, Vellore-632004, India
}

SUMMARY The free and bound sialic acid content of cerebrospinal fluid from patients with positive evidence (by CSF culture) of pyogenic and tuberculous meningitis was determined. The free sialic acid content was significantly raised only in cases of pyogenic meningitis, but not in tuberculous or other types of the disease.

The presence of free and bound sialic acid (Nacetylneuraminic acid) in human cerebrospinal fluid (CSF) has been noted by a number of workers (Jakoby and Warren, 1961; Saifer and Gerstenfeld, 1962; O'Toole et al., 1971a). Jakoby and Warren (1961) observed raised levels of total sialic acid in the CSF of patients with meningitis of unspecified aetiology. O'Toole et al. (1971a) reported abnormal concentration of free sialic acid in the CSF of patients with pneumococcal meningitis.

Of the various types of meningitis seen in adult neurological patients in India, a large percentage are diagnosed as tuberculous meningitis. The most dependable means of differentiating tuberculous from pyogenic meningitis is by CSF culture, but tubercle bacilli take about six to eight weeks to grow, and, furthermore, in patients who have been partially treated with antibiotics before admission, the results of culture are usually negative. In an earlier study (Balasubramanian et al., 1974), we observed raised free sialic acid values in the CSF of patients with pyogenic meningitis as compared with patients suffering from nonpyogenic chronic meningitis of various types and other neurological disorders. We have pursued this study in patients with positive evidence of tuberculous or pyogenic meningitis by CSF culture to assess the usefulness of determining free sialic acid levels for differentiating pyogenic from tuberculous meningitis.

\section{Methods}

Patients included in the study were mostly from the

(Accepted 24 August 1976.) neurological inpatient service of this hospital, admitted during the last one year period.

CSF was collected by lumbar puncture. Samples which were contaminated with any trace of blood or were xanthochromic were not included for analysis. Free and bound sialic acid in $0.2 \mathrm{ml}$ of the CSF was determined according to the method of Warren (1959), as modified by Saifer and Gerstenfeld (1962). Hydrolysis of the CSF sample for estimation of bound sialic acid was carried out at $80^{\circ}$ in $0.1 \mathrm{~N}$ $\mathrm{H}_{2} \mathrm{SO}_{4}$ for one hour (Warren, 1959).

\section{Results}

The Table gives the free and bound sialic acid levels in the CSF of patients with positive evidence for pyogenic meningitis, tuberculous meningitis, and mixed infections. The positive evidence for these infections is based, in addition to the clinical picture and other evidence, on the organisms grown from CSF in culture. A case of syphilitic meningitis, two cases of viral meningoencephalitis, and a number of control patients with non-infectious diseases are also included in the Table.

The bound sialic acid was frequently high in the cases of infection, both pyogenic and tuberculous meningitis. This is in accordance with the observations made by Jakoby and Warren (1961), Saifer and Gerstenfeld (1962), and O'Toole et al. (1971a), and may be explained on the basis of the increased protein content especially of the sialic acid containing immunoglobulins usually found in the CSF of these cases (O'Toole et al., 1971a,b; Balasubramanian et al., 1974). However, free sialic acid was found to be significantly increased only in the cases of pyogenic 
Table Free and bound sialic acid in the CSF of patients with meningitis

\begin{tabular}{|c|c|c|c|c|}
\hline \multirow[t]{2}{*}{ Diagnosis } & \multirow[t]{2}{*}{ Case } & \multicolumn{2}{|c|}{$\begin{array}{l}\text { CSF sialic acid } \\
(\mu \mathrm{mol} / \mathrm{l})\end{array}$} & \multirow[t]{2}{*}{$\begin{array}{l}\text { Organisms grown in culture } \\
\text { from CSF }\end{array}$} \\
\hline & & Bound & Free & \\
\hline Pyogenic meningitis & $\begin{array}{l}1 \\
2 \\
3 \\
4 \\
5\end{array}$ & $\begin{array}{r}410 \\
1450 \\
100 \\
95 \\
38\end{array}$ & $\begin{array}{r}89 \\
92 \\
620 \\
390 \\
80\end{array}$ & $\begin{array}{l}\text { Pneumococci } \\
\text { Pneumococci } \\
\text { Bacillus proteus } \\
\text { Bacillus proteus } \\
\text { Diplococci }\end{array}$ \\
\hline Mixed infections of pyogenic and & 1 & 1020 & 80 & Streptococci and tubercle bacilli \\
\hline tuberculous meningitis & 2 & 35 & 77 & Pneumococci and tubercle bacilli \\
\hline \multirow[t]{4}{*}{ Tuberculous meningitis } & $\begin{array}{l}1 \\
2\end{array}$ & $\begin{array}{r}130 \\
60\end{array}$ & $\begin{array}{l}22 \\
16\end{array}$ & $\begin{array}{l}\text { Tubercle bacilli } \\
\text { Tubercle bacilli }\end{array}$ \\
\hline & 3 & 70 & 13 & Tubercle bacilli \\
\hline & 4 & 220 & 20 & Tubercle bacilli \\
\hline & 5 & 32 & 26 & Tubercle bacilli \\
\hline \multirow[t]{2}{*}{ Viral meningoencephalitis } & 1 & 13 & 20 & Nil \\
\hline & 2 & 160 & 32 & Nil \\
\hline \multirow{2}{*}{$\begin{array}{l}\text { Syphilitic meningitis } \\
\text { Controls* }\end{array}$} & 1 & 300 & 38 & Nil \\
\hline & 9 patients & $\begin{array}{l}12-40 \\
\text { (range) }\end{array}$ & $\begin{array}{l}6-32 \\
\text { (range) }\end{array}$ & Nil \\
\hline
\end{tabular}

*Controls include nine patients with psychogenic disorders, muscular dystrophy, and idiopathic epilepsy.

meningitis. It may be noted that even the lowest value for free sialic acid in the CSF of the pyogenic patients ( $77 \mu \mathrm{mol} / \mathrm{l})$ is far higher than the highest values found in the CSF of patients with tuberculous and other types of meningitis and of the controls. This observation serves to differentiate the cases of pyogenic meningitis from the others. In no case of tuberculous meningitis was the free sialic acid increased over the highest control value.

\section{Discussion}

The present results confirm our earlier findings (Balasubramanian et al., 1974) in which the free sialic acid levels of CSF in eight patients with pyogenic meningitis and 24 patients with tuberculous meningitis were reported. Since CSF culture data were not positive in all the cases in the earlier report, the present study was undertaken. It is conceivable that the enzyme neuraminidase elaborated by the pyogenic organisms is responsible for the enhanced free sialic acid in the CSF of these patients (Gottschalk and Drzeniek, 1972). It is known that neuraminidase catalyses the cleavage of sialic acid from glycoproteins and gangliosides. The substrate for this enzyme in the patients with pyogenic infection may be either the glycoproteins and gangliosides of the nervous tissue, or the serum sialoglycoproteins present in the CSF.

Determination of free sialic acid levels in the CSF will be of help in the early diagnosis of and differentiation between pyogenic and tuberculous meningitis. An enhanced free sialic acid level (approximately $70 \mu \mathrm{mol} / 1$ as observed in the study) in the CSF is indicative of pyogenic meningitis caused by those organisms which elaborate neuraminidase. It has perhaps, only two disadvantages. One is that, in meningitis caused by several strains of meningococcis or $H$. influenzae which do not elaborate the enzyme neuraminidase (O'Toole et al., 1971a), the high freeo sialic acid levels in CSF cannot be expected. We had, only one positive case of $H$. influenzae meningitis with normal free sialic acid levels among the adul patients admitted during the last two years. Another disadvantage is that, in mixed infections of botho pyogenic and tuberculous organisms, free sialic acis levels will indicate only the pyogenic infection. It haso:however, the advantage in those cases where results ${ }^{+}$ of CSF culture are negative due to partial clinical treatment or otherwise. Even in cases of pyogenic meningitis where partial clinical treatment had been given, the increased free sialic acid level in CSF was found to persist (Balasubramanian et al., 1974). Furthermore, determination of free sialic acid is a relatively rapid and simple procedure in comparison with culture techniques. It will, therefore, serve as an additional useful test for differentiating pyogenic meningitis from tuberculous meningitis.

\section{References}

Balasubramanian, A. S., Raman, P. T., and Taori, G. M. (1974). Free and bound $\mathrm{N}$-acetylneuraminic acid in the cerebrospinal fluid in various neurological disorders. Indian Journal of Medical Research, 62, 781-787.

Gottschalk, A., and Drzeniek, R. (1972). Neuraminidase as a tool in structural analysis. In Glycoproteins, pp. 381-402. Edited by A. Gottschalk. Elsevier: Amsterdam.

Jakoby, R. K., and Warren, L. (1961). Identification and quantitation of $\mathrm{N}$-acetylneuraminic acid in human 
cerebrospinal fluid. Neurology (Minneap.), 11, 232-238. Saifer, A., and Gerstenfeld, S. (1962). Photometric

O'Toole, R. D., Goode, L., and Howe, C. (1971a). Neuraminidase activity in bacterial meningitis. Journal of Clinical Investigation, 50, 979-985.

O'Toole, R. D., Thornton, G. F., Mukherji, M. K., and Neogy, K. N. (1971b). Cerebrospinal fluid immunoglobulins in bacterial meningitis. Archives of Neurology (Chic.), 25, 218-224. determination of sialic acids in serum and cerebrospinal fluid with the thiobarbituric acid method. Clinica Chimica Acta, 7, 467-475.

Warren, L. (1959). The thiobarbituric acid assay of sialic acids. Journal of Biological Chemistry, 234, 1971-1975. 